\title{
OBSERVATÓRIO DA EDUCAÇÃO UNIVATES: AÇÕES E PERSPECTIVAS PARA O ENSINO DE MATEMÁTICA NA ESCOLA BÁSICA
}

\author{
Ieda Maria Giongo ${ }^{1}$, Márcia Jussara Hepp Rehfeldt ${ }^{2}$, Marli Teresinha Quartieri ${ }^{3}$
}

\begin{abstract}
Resumo: O presente artigo tem como objetivo explicitar um conjunto de resultados provenientes de um projeto de pesquisa e intervenção, desenvolvido na Universidade do Vale do Taquari (Univates) com fomento financeiro do Programa Observatório da Educação (Edital INEP/CAPES 049/2012). Pesquisadores, alunos de graduação e pós-graduação da Univates e professores de seis escolas de Educação Básica da região compunham a equipe de trabalho. Centralmente, a investigação teve como objetivo produzir movimentos de ruptura nos processos de ensino e de aprendizagem de Matemática na Escola Básica, tendo como referencial teórico-metodológico três tendências vinculadas ao ensino desta disciplina: etnomatemática, modelagem matemática e investigação matemática. Os resultados mostram a potência de aliar pesquisa acadêmica e práticas pedagógicas na Escola Básica no que se refere ao adensamento teórico-metodológico para docentes e pesquisadores.
\end{abstract}

Palavras-chave: Escola Básica. Observatório da Educação. Ensino de Matemática. Currículo.

\section{UNIVATES EDUCATION OBSERVATORY: ACTIONS AND PERSPECTIVES FOR TEACHING MATH IN PRIMARY SCHOOL}

\begin{abstract}
This article aims at reporting a set of outcomes originated from a research project and a intervention project, developed at Universidade do Vale do Taquari with the financial support of the Program Observatory for Education (Public Notice INEP/CAPES 049/2012). Researchers, undergraduate and graduate students from Univates and professors from six elementary schools in the region made up the work team. The main purpose of the investigation was producing disruptive movements in the math teaching and learning processes in primary schools, by having as a theoretical-methodological support three trends connected to the teaching of this course: ethnomathematics, mathematical modeling, and mathematical investigation. The results showed the possibility of combining academic research and
\end{abstract}

1 Doutora em Educação. Professora da Univates vinculada aos Programas de Pós-Graduação em Ensino e em Ensino de Ciências Exatas.

2 Doutora em Informática na Educação. Professora da Univates vinculada aos Programas de PósGraduação em Ensino e em Ensino de Ciências Exatas.

3 Doutora em Educação. Professora da Univates vinculada aos Programas de Pós-Graduação em Ensino e em Ensino de Ciências Exatas. 
teaching practices in primary schools, regarding theoretical-methodological densification for teachers and researchers.

Keywords: Primary School, Education Observatory, Mathematics Teaching, Syllabus.

\section{Introdução: a emergência de um projeto de pesquisa intervenção}

Entre 2013 e 2017 desenvolveu-se, na Universidade do Vale do Taquari (Univates), um projeto de pesquisa intervenção vinculado ao programa governamental Observatório da Educação (Edital INEP/CAPES 049/2012) cujo objetivo central consistia em promover movimentos de ruptura nos processos de ensino e de aprendizagem da Matemática na Escola Básica. A ideia do projeto foi gestada a partir da inquietação de um grupo de pesquisadoras da Instituição com relação à formação continuada de docentes da Escola Básica e a crescente produção de dissertações e teses enfocando, precisamente, questões relativas à docência em Matemática nos Anos Iniciais e Finais do Ensino Fundamental. Em efeito, tal aumento e as respectivas discussões acerca dos resultados das pesquisas parecem ficar restritas às universidades, periódicos e congressos da área, tendo pouco reflexo nas práticas pedagógicas nas salas de aula. A constatação levou o grupo de pesquisadoras, apoiadas em Nacarato (2016), a enveredar por um projeto de pesquisa intervenção que congregasse professores da Escola Básica e alunos da graduação e pós-graduação com o intuito de aproximar investigações de um conjunto de escolas de Educação Básica da região do Vale do Taquari. Em efeito:

Qual é, de fato, a centralidade dos professores nesse debate? Se, por um lado, a formação docente é central nas pautas dessas políticas, por outro, do ponto de vista da pesquisa, esse é o campo de investigação que reúne o maior número de trabalhos, haja vista o número de artigos submetidos aos grupos de trabalhos de formação docente a cada evento: tanto o GT08, da ANPEd, quanto o GT07, da Sociedade Brasileira de Educação Matemática (SBEM), são grupos que recebem um número expressivo de trabalhos, e, no próprio GT19, Educação Matemática, da ANPEd, o maior número de trabalhos recebidos anualmente se centra nessa temática (NACARATO, 2016, p. 701).

O grupo em questão também, há tempos, se ocupava com formação inicial e continuada de professores e atuava em um Mestrado Profissional em Ensino de Ciências Exatas, orientando estudantes em três tendências no ensino da Matemática: etnomatemática, modelagem matemática e investigação matemática. Assim, mesmo com um número expressivo de trabalhos na área, havia a preocupação em como operar com estas ideias de modo que os resultados destes impactassem na Escola Básica, lócus da realização de muitas investigações. Nessa ótica, optou-se, então, por efetivar um conjunto de ações, num espaço de quatro anos, que tinha como característica pesquisar com a escola básica, em detrimento de "na escola", "sobre a escola" ou "a escola". Por conta disso, as seis escolas escolhidas para o projeto foram denominadas parceiras. 
A partir dos aportes teórico-metodológicos escolhidos, o grupo em questão passou a ser formado por quatro pesquisadoras da Universidade, seis bolsistas de mestrado (três a cada biênio), seis professores da Escola Básica e seis estudantes de graduação. Os professores das escolas, alunos de graduação e pós-graduação foram contemplados com uma bolsa de remuneração mensal, sendo que os mesmos estavam comprometidos a desenvolver uma série de atividades que foram construídas e desenvolvidas ao longo dos quatro anos. Ademais, ao longo do processo, voluntários foram se agregando, dentre eles, uma bolsista de pós-doutorado, mestrandos e professores da Escola Básica. Em síntese, desenvolveram-se:

- Estudo e discussão de planos de ensino das Séries Iniciais e de Matemática das Séries Finais do Ensino Fundamental com vistas à reestruturação metodológica no currículo de Matemática nas escolas parceiras.

- Estudo, junto aos professores das escolas parceiras, de três tendências no âmbito da Educação Matemática para a Educação Básica: Modelagem Matemática, Etnomatemática e Investigação Matemática.

- Elaboração, implementação e avaliação de propostas metodológicas e curriculares envolvendo as tendências em estudo com o intuito de fomentar a emergência de boas práticas pedagógicas, especialmente no âmbito da disciplina Matemática.

- Acompanhamento sistemático dos alunos das escolas parceiras na Prova BRASIL e no SAEB, bem como verificar as modificações ocorridas em suas aprendizagens no período de realização da investigação.

- Elaboração, aplicação, correção e avaliação dos resultados de provas simuladas formuladas pela equipe do projeto, objetivando a melhoria no desempenho dos alunos nas avaliações externas.

- Aproximação da Universidade, os Cursos de Licenciatura e o Mestrado das Escolas de Educação Básica, incentivando articulações entre todos os atores ali envolvidos.

- Elaboração de cursos de formação continuada para os professores dos Anos Iniciais e de Matemática nos Anos Finais do Ensino Fundamental, enfocando as tendências elencadas.

- Socialização dos resultados das investigações com Escolas de Educação Básica e Instituições de Ensino Superior como forma de compartilhar conhecimentos e práticas pedagógicas inovadoras, integrando, assim, várias instâncias educacionais brasileiras.

Especificamente, neste relato, abordaremos um conjunto de resultados que mostram a potência de aliar pesquisa acadêmica e práticas pedagógicas na Escola Básica no que se refere ao adensamento teórico-metodológico para docentes e pesquisadores. 
Por conta disso, a seguir, explicitaremos os referenciais teórico-metodológicos que sustentaram a investigação.

\title{
Acerca dos referenciais teórico-metodológicos
}

Como expresso anteriormente, as investigadoras da Univates atuam no Mestrado Profissional em Ensino de Ciências Exatas, orientando dissertações tendo como referencial teórico três tendências do ensino de Matemática: investigação matemática, modelagem matemática e etnomatemática.

Com relação à investigação matemática, vale destacar os estudos de Ponte, Brocardo e Oliveira (2009). Os referidos autores aludem que fazer investigação em sala de aula - em especial àquela vinculada à disciplina Matemática - pressupõe formular questões que nos interessam "para as quais não temos resposta pronta, e procuramos essa resposta de modo tanto quanto possível fundamentado e rigoroso" (p. 9). Os autores ainda comentam que, nessa perspectiva teórica, não é necessário se trabalhar com problemas considerados difíceis, mas apenas evidenciar "questões que nos interpelam e que se apresentam no início de modo confuso, mas que procuramos clarificar e estudar de modo organizado" (ibidem, p. 9). Assim:

\begin{abstract}
Em numerosas experiências já empreendidas com trabalho investigativo, os alunos têm mostrado realizar aprendizagens de grande alcance e desenvolver um grande entusiasmo pela Matemática. Apesar disso, não encaramos as investigações matemáticas como a chave que permite por si só resolver todos os problemas do ensino da Matemática. Há muitas outras atividades a realizar na sala de aula. Há muitos fenômenos e problemas a ter em consideração [...]
\end{abstract}

Ademais, os mesmos autores ainda inferem que um dos objetivos centrais ao se operar com esta metodologia em sala de aula é "que o aluno aprenda como ser um investigador perspicaz, e para isso tem que fazer investigação" (Ibidem, p. 37). O processo de investigar, ainda para os autores, envolve quatro momentos, a saber:

Quadro 1 - Passos de uma investigação matemática

\begin{tabular}{|l|l|}
\hline $\begin{array}{l}\text { Exploração e formulação de } \\
\text { questões }\end{array}$ & $\begin{array}{l}\cdot \text { Reconhecer uma situação problema } \\
\cdot \text { Explorar a situação problemática } \\
\cdot \text { Formular questões }\end{array}$ \\
\hline Conjecturas & $\begin{array}{l}\cdot \text { Organizar dados } \\
\cdot \begin{array}{l}\text { Formular conjecturas (e fazer afirmações sobre uma } \\
\text { conjectura) }\end{array}\end{array}$ \\
\hline Testes e reformulação & $\begin{array}{l}\cdot \text { Realizar testes } \\
\cdot \text { Refinar uma conjectura }\end{array}$ \\
\hline Justificação e validação & $\begin{array}{l}\cdot \text { Justificar uma conjectura } \\
\cdot \text { Avaliar o raciocínio ou o resultado do raciocínio }\end{array}$ \\
\hline
\end{tabular}

Fonte: (PONTE; BROCARDO; OLIVEIRA, 2009, p. 21) 
A segunda tendência que alicerçou as investigações é a modelagem matemática. Barbosa (2003, p. 2) alude que as ações desta podem contribuir para "colocar lentes críticas sobre as aplicações da matemática" e que esta tendência "pode potencializar a intervenção das pessoas nos debates e tomadas de decisões sociais que envolvem a aplicação da matemática, o que me parece ser uma contribuição para alargar as possibilidades de construção e consolidação de sociedades democráticas" (Ibidem, p. 2). Ao compreender essa dimensão, é provável que os alunos entendam que a Matemática é uma construção humana e, portanto, é possível seus fundamentos e história serem compartilhados e compreendidos não apenas por um seleto grupo de iluminados. Práticas pedagógicas alicerçadas nessa tendência podem ter a sala de aula como lócus privilegiado. Segundo Barbosa (2003, p. 4): "Portanto, ao tomar o argumento de que Modelagem leva os alunos a compreender o papel sociocultural da matemática, quero justamente enfatizar esse aspecto nas atividades de sala de aula”. Assim, ainda para ele:

Para desenvolver a argumentação por uma perspectiva sociocrítica para a Modelagem, começo pelo reconhecimento de que as aplicações da matemática estão amplamente presentes na sociedade e trazem implicações para a vida das pessoas. Seja no mundo do trabalho, nas diversas áreas científicas, nas tarefas cotidianas, etc., a matemática desempenha um papel subtil (BARBOSA, 2003, p.3).

Bassanezi (2011, p. 16) expressa que "a modelagem matemática consiste na arte de transformar problemas da realidade em problemas matemáticos e resolvê-los interpretando suas soluções na linguagem do mundo real”. Nessa ótica, Burak (1992) expressa que nesse tipo de proposta, o professor tem o papel de mediador da relação ensino-aprendizagem, isto é, atua como orientador do trabalho pedagógico em um processo de, resolver as dúvidas dos estudantes e propor novos pontos de vista com relação ao problema tratado. $\mathrm{O}$ mesmo autor ainda expressa que

$\mathrm{Na}$ Modelagem Matemática não existe o modelo "certo" ou "errado" ou modelo "verdadeiro" ou "falso"; existe o modelo "mais" ou "menos" refinado, e isto é muito diferente de estar "certo" ou "errado". Um modelo é mais refinado quando diz mais a respeito do objeto de estudo, é de predizer com maior exatidão, pois relaciona mais variáveis significativas do problema [...] (BURAK, 1992, p. 314).

Noutro artigo, Burak (2004) expressa questões vinculadas à aprendizagem e ao interesse dos estudantes tendo em vista que, para ele, poderá haver ganho significativo para a aprendizagem quando os estudantes realizam tarefas cujas temáticas sejam de seu interesse.

A terceira tendência problematizada no projeto apregoa que aspectos socioculturais também são relevantes ao campo da Etnomatemática, a terceira tendência problematizada no projeto. Autores como Knijnik et al (2012, p.13) mostram que, embora passaram-se 40 anos de sua emergência, a Etnomatemática "segue interessada 
em discutir a política do conhecimento dominante praticada na escola”. Neste sentido, para elas:

O pensamento etnomatemático está centralmente interessado em examinar as práticas fora da escola, associadas a racionalidade que não são idênticas à racionalidade que impera na Matemática Escolar, com seus estreitos vínculos com a razão universal instaurada pelo Iluminismo. Mas é preciso que se diga: olhar para estas outras racionalidades, sem jamais se esquecer do que está no horizonte, é pensar outras possibilidades para a Educação Matemática praticada na escola (KNIJNIK et al, 2012, p.18, grifos nossos).

O assim chamado "pai da etnomatemática", Ubiratan D’Ambrósio (1997, p.116) expressa que no "processo de glorificação dos saberes matemáticos provenientes da Europa Ocidental, às civilizações da América e àquelas expulsas da África pelo escravismo" foram impostos não apenas "determinadas formas de pensar e de explicar, mas também de propriedade e produção. Deste modo, no início do século XIX, há uma tentativa de "universalizar as novas ciências"' (Ibidem, 1997, p. 116). Em adição, "essa tentativa de universalização culminou com a consolidação da matemática como 'o modo de pensamento por excelência do pensamento científico”" (Ibidem, p. 115).

Nesse sentido, as matemáticas escolar e acadêmica podem ser pensadas como modos particulares de ver o mundo e as relações entre as pessoas, sobretudo no ensino de Matemática. A esse respeito, Knijnik (2007, p. 3) mostra que "fomos de tal modo sujeitados pelo que é usualmente chamado 'conhecimentos acumulados pela humanidade", que não compreendemos que se trata de "uma parcela muito particular do conjunto muito mais amplo e diverso do que vem sendo produzido ao longo da história pela humanidade" (Ibidem, p. 3). A referida autora ainda argumenta que a matemática acadêmica também é uma etnomatemática, "praticada pelos matemáticos que habitam a cultura acadêmica" (IBIDEM, p.12), sendo que a supremacia dessa particular matemática se dá na medida em que ela é "legitimada socialmente como ciência", ocupando, assim, "um lugar de destaque entre as demais etnomatemáticas" (IBIDEM, p. 9). Por fim, Knijnik (2007) expressa que, como educadores "estamos inevitavelmente comprometidos em favorecer o acesso aos saberes matemáticos hegemônicos que operam na sociedade contemporânea" (Ibidem, p. 9, grifos nossos).

Munidos destes referenciais, o grupo de pesquisadores, dentre outras ações, elaborou e efetivou práticas pedagógicas nas seis escolas parceiras, envolvendo estudantes dos Anos Iniciais, Educação Infantil e Anos Finais do Ensino Fundamental. Na próxima seção, serão enfatizados os resultados advindos destas intervenções, sobretudo no que se refere aos professores destes educandários. 


\section{As práticas pedagógicas e os professores da Escola Básica}

Em cada período letivo, os professores da Escola Básica bolsistas deveriam, progressivamente, propor e implementar práticas pedagógicas inovadoras, alicerçadas nas três tendências, a saber: etnomatemática, modelagem matemática e investigação matemática. Embora, a maior responsabilidade por estas ações estar vinculadas aos professores bolsistas, o grupo de pesquisa sempre optou por envolver a maior quantidade possível de professores das seis escolas parceiras. Em função disso, a primeira ação envolveu conversações com as equipes diretivas e pedagógicas das escolas, expondo o que nos propúnhamos. Em especial, havia o propósito de que as escolas parceiras tivessem acesso a estudos teórico-metodológicos de todas as três tendências, não se restringido a uma ou duas delas. Ademais, as equipes diretivas e os professores solicitaram que as formações nas escolas deveriam abordar, ao longo do projeto, conteúdos específicos de frações, geometria e álgebra, envolvendo Anos Iniciais e Ensino Fundamental.

A fim de que tais ações reverberassem na escola, os docentes bolsistas deveriam participar das reuniões de terça-feira à noite nas dependências da Univates. $\mathrm{O}$ grupo era formado, então, por eles, pesquisadores, mestrandos e bolsistas de graduação. Com o passar do tempo, voluntários mestrandos e professores da Escola Básica, bem como uma bolsista de pós-doutorado foram se juntando ao projeto. Nestas reuniões, predominavam discussões teórico-metodológicas sobre as três tendências, construção e análise de práticas pedagógicas. Os mestrandos e bolsistas de graduação também deveriam fazer suas práticas investigativas nas seis escolas parceiras com a consequente discussão no grupo. Paralelo a isso, em muitas reuniões também foram planejadas as atividades de álgebra, geometria e frações, por demanda das escolas.

No primeiro ano de vigência do projeto, cada docente pôde escolher uma tendência para sustentar suas práticas pedagógica. As atividades eram construídas no grupo e efetivadas nas turmas em que atuavam. Na mesma ótica, cada mestrando ficou responsável por fazer suas investigações em duas escolas, um em cada tendência. Dos seis bolsistas de graduação, cada dupla também operava com uma tendência. A todo o momento, os docentes eram incentivados a participar de eventos, mas não mais como ouvintes e, sim, apresentando suas práticas pedagógicas, analisando-as criticamente. Assim, desde o primeiro ano, os docentes participaram de eventos importantes na área, incluindo nacionais. Em paralelo, os docentes da Escola Básica recebiam nos seus locais de trabalhos os mestrandos e bolsistas de graduação, fazendo a devida interlocução com os demais docentes. Ademais, as formações nas escolas iniciaram em 2013, sempre com a presença de pesquisadores, bolsistas de mestrado e graduação e do docente bolsista que nelas atuava.

No segundo ano, os docentes prepararam outra prática pedagógica envolvendo mais uma tendência, continuaram a participar de eventos com apresentação de trabalhos e passaram a ter mais convívio com a pesquisa. Houve, sobretudo, sensível progresso na escrita das atividades e os mesmos expressaram estar mais confiantes em apresentar e escrever sobre as próprias práticas. Os resultados destas podem ser encontradas no 
primeiro de quatro livros (MUNHOZ; GIONGO, 2014). Verifica-se, nesta obra, que os escritos envolveram todos os atores participantes do projeto e os capítulos foram escritos em parceria, como, por exemplo, docentes da Escola Básica e mestrandos, bolsistas de graduação e mestrandos, dentre outros.

No segundo ano, além de preparar as formações continuadas, os professores bolsistas deveriam obter o auxílio de um colega com o intuito de, alicerçados na terceira tendência que ainda não havia sido problematizada por eles, operar com práticas pedagógicas via docência compartilhada, conforme expresso nos capítulos do segundo livro (GIONGO; MUNHOZ, 2016). Ressalta-se também que os livros começaram a ser usados nas reuniões pedagógicas em cada uma das seis escolas, como materiais de apoio para estudos. Também houve a preocupação de distribuir cópias impressas dos mesmos para as escolas da rede estadual de ensino, via colaboração da Coordenadoria Regional de Educação.

Paralelo a tais atividades, ocorreram dois importantes seminários na Universidade, denominados "Seminário Observatório da Educação I" e Seminário Observatório da Educação II, com a presença de professores da região e docentes que pesquisavam nas três tendências foco do projeto. Por essa razão, os livros também contam com capítulos destes convidados, enfocando práticas pedagógicas e referenciais teóricos alusivos ao ensino de Matemática. Os integrantes do grupo de pesquisa apresentaram trabalhos e ofertaram oficinas durante o evento, enfatizando também questões teóricas advindas das três tendências.

No terceiro ano, ocorreram as formações, nas escolas parceiras, relativas à geometria e, em duplas, os professores deveriam compor práticas alicerçadas numa das três tendências. Além disso, os mesmos foram agentes importantes na formação efetivada, via videoconferência, com um grupo de professores e graduandos em Pedagogia e Matemática da Universidade do Maranhão. Tal formação não estava inicialmente prevista, mas por conta da entrada, no projeto, de uma mestranda voluntária que residia em São Luís, MA, ocorreu interlocuções com docentes e pesquisadores maranhenses, o que determinou a constituição de duas web conferências. Nestas, docentes e pesquisadores dos dois estados puderam trocar experiências pedagógicas em Matemática.

Aliado a isso, apresentaram suas propostas de investigação em sala de aula para um grupo de professores dos municípios de Teutônia e Estrela, RS, a convite das Secretarias da Educação. Neste tempo, os professores voluntários passaram a também escrever suas práticas pedagógicas, apresentando trabalhos e em congressos e seminários. Podem ser visualizados alguns destes resultados no livro III (MUNHOZ; GIONGO, 2017). A troca de bolsistas mestrandos (com a entrada de três novos discentes) também proporcionou novos estudos sobre as tendências e, a partir de então, as investigações destes passaram a ser discutidas com maior ênfase no grupo, sendo perceptível que os docentes da Escola Básica participavam com maior propriedade acadêmica acerca das tendências em questão. 
No quarto ano de vigência do projeto, os mesmos docentes prepararam e implementaram atividades para formação contemplando Álgebra e ficaram responsáveis por novamente alicerçar suas práticas numa das tendências. Ressalta-se, sobretudo, que estes movimentos permitiram que alguns professores se aventurassem a apresentar seus trabalhos em eventos de porte nacional, produzindo artigos que estão em fase de submissão. Nesta época, também, uma das professoras realizou processo seletivo e foi aprovada para o Mestrado em Ensino da Univates, pesquisando a temática investigação matemática no nono ano do Ensino Fundamental. O quarto livro (GIONGO; MUNHOZ, 2017) apresenta alguns resultados provenientes das formações e das práticas pedagógicas efetivadas.

Com o término do projeto, três dos seis bolsistas e todos os voluntários continuaram a fazer parte do grupo de pesquisa que, atualmente, via auxílio do Conselho Nacional de Desenvolvimento Científico e Tecnológico (CNPq), se ocupa em examinar questões vinculadas ao ensino, aprendizagem e avaliação, tendo como parceira uma Secretaria Municipal de Educação da região. Entendemos que o grupo de pesquisa se consolidou durante a execução do projeto e que poderá seguir investigando ensino de Matemática na Escola Básica tendo presente a premissa central, ou seja, pesquisar com a escola e a universidade. Deste modo, docentes da Escola Básica e pesquisadores da universidade se adensam teórica e metodologicamente, como enfatizaremos a seguir, nas considerações finais.

\section{Considerações finais}

Entendemos que um projeto de intervenção de quatro anos que envolva pesquisadores, professores da Escola Básica, alunos de graduação e de pós-graduação apresenta potência para que se repensem os processos de ensino e de aprendizagem da Matemática na Escola Básica, sobretudo se considerarmos a máxima de "pesquisar com a escola". Certamente, se constitui um grande desafio enveredar por este caminho tendo em vista que

\footnotetext{
A construção de parcerias é um processo longo, demanda respeito pelo trabalho do outro: os professores acadêmicos precisam colocar-se à escuta dos professores da escola básica e trabalhar na perspectiva de que o que estes têm a dizer tem importância e precisa ser o ponto de partida para um trabalho coletivo; os professores da escola básica, por sua vez, à medida que sentem confiança nos formadores, aderem à proposta de trabalho coletivo. Assim, a parceria potencializa aprendizagens recíprocas. (NACARATO, 2016, p.713).
}

As aprendizagens recíprocas de que fala Nacarato (2016) foi importante para os docentes da Escola Básica, ao explicitarem suas investigações em sala de aula em eventos e na escrita de artigos, tornaram-se pesquisadores da própria prática, para além de simplesmente fazer uso de práticas efetivadas por outros. Por sua vez, os pesquisadores 
da Universidade, mestrandos e bolsistas de graduação puderam compreender, de modo mais efetivo, o dia a dia de uma escola de educação básica.

Importante também destacar a produtividade do contato direto destes professores com alunos de graduação e pós-graduação. De fato, ao estudarem as propostas dos colegas de investigação bem como de outros, contataram com referenciais teóricometodológicos que foram centrais para a construção de suas próprias práticas. Entendemos não mais ser possível pensarmos em formações continuadas que se separem teoria e prática pois ambas se conectam de forma a propiciar práticas alicerçadas teoricamente, considerando o contexto em que são geradas.

Por fim, expressamos que as três tendências escolhidas para sustentar tais práticas etnomatemática, modelagem matemática e investigação matemática - se apresentaram como potentes para a obtenção dos resultados no que se refere às práticas pedagógicas tendo em vista sua pouca expressão nas escolas de Educação Básica. Entretanto, não se configuram como únicas possibilidades pois estamos cientes de que o exame de outras teorizações pode também produzir outros modos de ensinar e aprender matemáticas.

Acreditamos que cada espaço escolar e universidade podem, a partir de pesquisas já em andamento, optar por esta modalidade de parceria que pode acrescentar importantes elementos para que se siga pensando o ensino de Matemática. Em especial, ao dar visibilidade a distintos modos de operar matematicamente, pode-se também "alimentar a possibilidade de trilhar outros caminhos no âmbito da Educação Matemática” (KNIJNIK et al, 2012, p. 85) neste ciclo de escolarização cujo tem sido alvo de muitas críticas por não apresentar resultados considerados satisfatórios no que se refere à aprendizagem dos estudantes.

\section{Referências}

BARBOSA, J. C. Modelagem Matemática e a Perspectiva Sócio-crítica. Anais... II SEMINÁRIO INTERNACIONAL DE PESQUISAS EM EDUCAÇÃO MATEMÁTICA GT MODELAGEM MATEMÁTICA. Santos, 2003. Disponível em http://www.somaticaeducar.com.br/arquivo/material/142008-11-01-15-44-48.pdf. Acesso: jan. 2018.

BASSANEZI, R. C. Ensino-aprendizagem com Modelagem Matemática: uma nova estratégia. 3. ed. São Paulo: Contexto, 2011.

BURAK, D. Modelagem Matemática: ações e interações no processo de ensinoaprendizagem. Campinas. 1992. Tese (Doutorado em Educação) - Programa de PósGraduação em Educação. Universidade Estadual de Campinas, Campinas, SP, 1992.

BURAK, D. Modelagem Matemática e a Sala de Aula. In: Anais I EPMEM - Encontro Paranaense da Modelagem Na Educação Matemática., 2004, Londrina. Anais ... I EPMEM, 2004.

D’AMBRÓSIO, U. Transdisciplinaridade. São Paulo: Palas Athena, 1997. 
GIONGO, I. M.; MUNHOZ, A. Vier. Observatório da Educação II: experiências curriculares no ensino de matemática na escola básica. Porto Alegre: Evangraf, 2016. Disponível em http://www.univates.br/editora-univates/media/publicacoes/116/pdf_168.pdf. Acesso em: janeiro de 2018.

GIONGO, I. M.; MUNHOZ, A. V. Observatório da Educação IV: currículos e práticas pedagógicas. Porto Alegre: Evangraf, 2017. Disponível em http://www.univates.br/editoraunivates/publicacao/232. Acesso em: janeiro de 2018.

KNIJNIK, G. Mathematics education and the Brazilian Landless Movement: three different mathematics in the context of the struggle for social justice. Philosophy of Mathematics Education Journal, v.21, p. 1-18, 2007.

KNIJNIK, G. et al. Etnomatemática em movimento. Belo Horizonte: Autêntica, 2012.

MUNHOZ, A. V.; GIONGO, I. M. (orgs). Observatório da Educação I: tendências no ensino da matemática. Porto Alegre: Evangraf, 2014. Disponível em http://www.univates.br/ editora-univates/media/publicacoes/116/pdf_116.pdf. Acesso em:

MUNHOZ, A. V.; GIONGO, I. M. (orgs). Observatório da Educação III: práticas pedagógicas na educação básica. Porto Alegre: Evangraf, 2017. Disponível em http://www. univates.br/editora-univates/publicacao/230. Acesso em:

NACARATO, A. A parceria universidade - escola: utopia ou possibilidade de formação continuada no âmbito das políticas públicas? In: Revista Brasileira de Educação. v. 21 n. 66 jul.-set. 2016. Disponível em http://www.scielo.br/pdf/rbedu/v21n66/1413-2478rbedu-21-66-0699.pdf. Acesso em: jan. 2018.

PONTE, J. P.; BROCARDO, J.; OLIVEIRA, H. Investigações matemáticas na sala de aula. Belo Horizonte: Autêntica, 2009. 